\title{
Minimizing Direct Deposition of Pesticides into Waterways Associated with Indian River Citrus Production
}

\author{
Chris Wilson ${ }^{1}$, Ed Stover, and \\ Brian Boman
}

ADDITIONAL INDEX WORDs. best management practice, BMP, Indian River citrus, pesticide, copper

SumMary. Off-target deposition of pesticidal spray material is both an economic loss to the grower and a potential environmental problem in southern Florida. This study evaluated the reduction in non-target deposition of copper resulting from different approaches to spraying row-ends in typical Indian River citrus (Citrus) production systems. Using copper as a model pesticide, applications were made in a commercial citrus grove in June and July 2001. Non-target deposition on the water surface within an adjacent drainage canal, as well as on surrounding ground surfaces, was measured using Teflon spray targets. Specific row-end spraying scenarios included: 1) leaving both banks of nozzles on while turning; 2) turning the outside-facing nozzles off (leaving tree-facing nozzles on); 3) turning both banks of nozzles off at the tree trunk; and 4) turning all nozzles off at the end of the foliage of the last tree within the row. Deposition directly onto surface water contained within drainage canals was reduced significantly when nozzles were turned off at the last tree within a row, or when the outside-facing

University of Florida/IFAS, Indian River Research and Education Center, 2199 South Rock Road, Fort Pierce, FL 34945

Acknowledgments. The authors wish to thank Jane Ferguson-Foos (Florida Department of Agriculture and Consumer Services) for her support and guidance, and Peter Strimple, Robert Minerva, James Salvatore, Michael Boman, and Michael Poult for their technical assistance. This project was funded by USEPA R4 through FDACS.

Florida Agricultural Experiment Station Journal Series No. R-10218.

${ }^{1}$ To whom correspondence should be addressed. Email address: pcwilson@ifas.ufl.edu 
nozzles-only were turned off through the turn. Likewise, deposition was reduced on ground surfaces adjacent to the sprayer under the same scenarios. No differences were observed on ground surfaces on the opposite side of the canal. Significant reductions in direct application of agrichemicals to surface waters within Indian River citrus production groves can be achieved by turning nozzles off when turning from one tree row into the next.

$\mathrm{T}$ The Indian River Lagoon (IRL) stretches $249.4 \mathrm{~km}$ (155 miles) from Volusia County southward to northern Palm Beach County. Historically, the IRL drainage basin was long and narrow. However, construction of an extensive canal system during the early 1900s more than doubled the size of the IRL drainage basin [Indian River Lagoon National Estuary Program (IRLNEP), 1996]. These canal systems were originally designed to drain wetlands for development. Today, this network of canals collects and transports large volumes of storm water runoff from a variety of land-uses, including land used for citrus production. Pesticide losses from citrus groves have been identified as a concern within the St. Lucie Estuary (SLE) and IRL drainage basins (Boman et al., 2000).

Off-target deposition of spray material is both an economic loss to the grower and a potential environmental problem. Much work has documented factors and the possible magnitude of spray drift in agricultural production systems (Spray Drift Task Force, 1997). Differences in canopy characteristics, wind, relative humidity (RH), planting density, and other factors may all significantly affect spray drift (reviewed by Stover et al., 2003). Smaller droplets are generally more prone to drift, with ground deposits typically being greatest within $15.2 \mathrm{~m}(50 \mathrm{ft})$ of the sprayer (Fox et al., 1993; Hobson et al., 1993; Johnson, 1995; Salyani and Cromwell, 1992; Walklate, 1992). The percentage of material drifting off-site increases with both wind speed and decreased droplet size.

The potential for surface water contamination in the Indian River (IR) area is not restricted to long-range drift of spray materials as is common in many agricultural areas. Most of these groves are situated on poorly drained soils with shallow hardpans and perched water-tables. These groves are almost always bedded to expedite drainage and provide adequate rooting space for the trees. Groves are designed so that rainfall drains rapidly from the beds through a series of water furrows connected to drainage ditches and larger canals (Figs. 1 and 2). These ditches and canals represent a direct linkage to the IRL and the SLE, making minimization of pesticide losses from production areas especially important. These ditches and canals also serve as aquatic habitat for a variety of invertebrate, fish, bird, and mammal species. Direct deposition of applied pesticides to the water surfaces of adjacent ditches and canals may present significant ecological risks, depending on the applied pesticide.

Since lateral drainage ditches and canals are often located perpendicular to tree rows, shutting off sprayer nozzles when approaching the end of tree rows should reduce drift of pesticides into these non-target surface water bodies (Fig. 2). In practice, spray technicians may not always turn sprayers off at the end of tree rows because of preoccupation with several aspects (scanning for oncoming traffic and obstacles, avoiding water furrow pipes, etc.) of safely exiting the row and making a $180^{\circ}$ turn into the next row, especially if they are driving in a water furrow. However, no formal studies have confirmed the efficacy of this practice.

This study evaluated the efficacy of turning sprayer nozzles off at row ends as a proposed best management practice (Boman et al., 2000) for preventing non-target deposition of pesticides in surface water connections such as irrigation and drainage ditches. This study also estimated direct deposition on ground surfaces that translate into wasted product, as well as another potential source of surface water contamination through surface water runoff.

\section{Materials and methods}

STUdy sITE. This study was conducted within a commercial, doublebedded citrus grove located in St. Lucie County, Fla. This grove was planted with white 'Marsh' grapefruit (Citrus paradisi) [on sour orange ( $C$. aurantium) rootstock] trees that were greater than 20 years old and were approximately $5.5 \mathrm{~m}(18 \mathrm{ft})$ tall. Distance between tree rows averaged $8.69 \mathrm{~m}$ $(28.5 \mathrm{ft})$ both across bed tops and furrows. These studies were conducted along a drainage ditch that separated two blocks of citrus within the grove (Fig. 2). This ditch was located approximately $8.2 \mathrm{~m}(27 \mathrm{ft})$ from the edge of the last tree within each row. The ditch itself was $7.6 \mathrm{~m}(25 \mathrm{ft})$ wide. The vertical distance from the ground surface down to the surface of the water within the ditch was approximately $1.65 \mathrm{~m}(5.4 \mathrm{ft})$.

Pesticide applications. Copper was used as a model pesticide because of its low human toxicity and its stable disposition, having few special handling and storage requirements for accurate analysis. Copper is routinely used in fungicidal applications to commercial

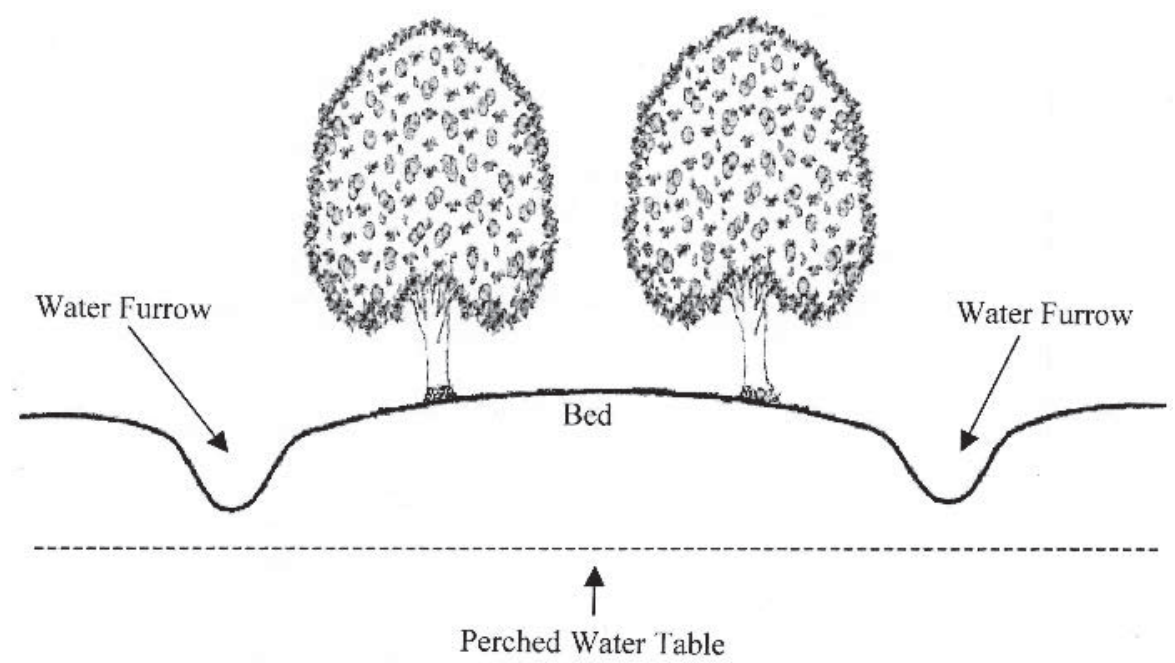

Fig. 1. Cross-sectional view of double-bedded citrus production. The water furrows provide drainage for each bed. 


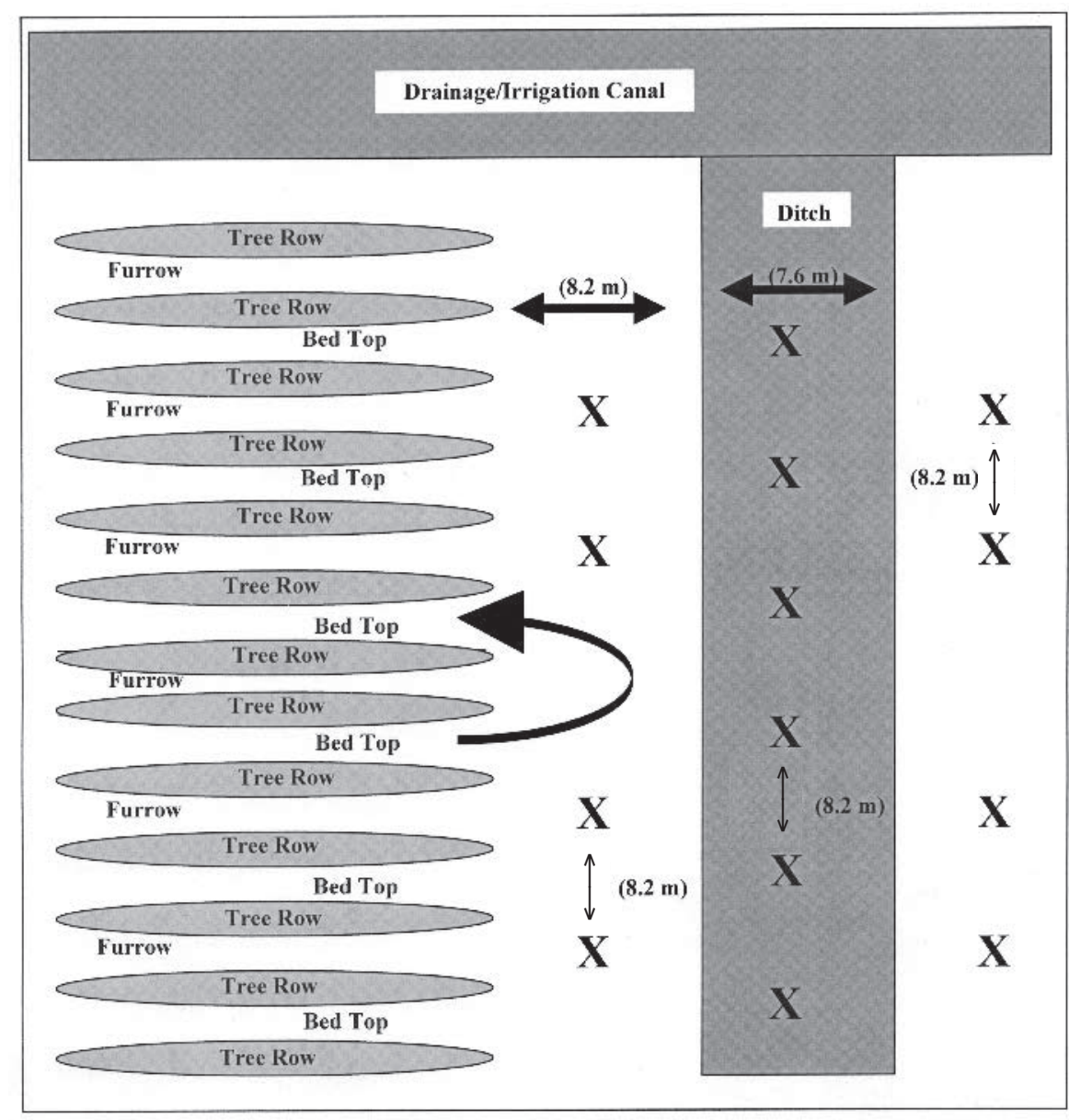

Fig. 2. Sample layout of targets during the study. " $X$ " = positions of Teflon targets. The curved arrow traces the sprayer path from one bed-top to the next. $(1.0 \mathrm{~m}=3.28 \mathrm{ft})$.

citrus in the region. Copper applications were made in June and again in July 2001, using a Durand Wayland Super Spray 500 (LaGrange, Ga.), power-take-off(PTO)-driven air-blast sprayer pulled by a New Holland (New Holland, Pa.) tractor $(70 \mathrm{hp})$. The sprayer was equipped with 20 nozzles (10 on each side). Specific nozzling arrangement included five No. 5 TeeJet (Spraying Systems Co., Wheaton, Ill.) discs on the bottom and five No. 6 discs on the top of each nozzle bank with TeeJet $4 \mathrm{~S}$ cores. The ground application speed for all applications was $3.2 \mathrm{~km} \cdot \mathrm{h}^{-1}(2 \mathrm{mph})$. The application rate was $1403.1 \mathrm{~L} \cdot \mathrm{ha}^{-1}$ (150 gal/acre). Evaluations were made with the tractor spraying only bed-tops. Within this type of double-bedded grove, pesticide applications to the furrow side of the trees are made after the sprayer is adjusted for tree elevation differences. The terminal 10 trees in each row were sprayed for each test replication.

Copper applications were made using a copper hydroxide formulated product (Champion, Agtrol Chemical Products, Houston); $12 \mathrm{lb}(5.4 \mathrm{~kg})$ of formulated product was mixed in $1892.7 \mathrm{~L}(500 \mathrm{gal})$ of water for each set of studies. The formulated product contains $77 \%$ a.i. (copper hydroxide) and $50 \%$ copper metallic. Applications were started before $0800 \mathrm{HR}$ and lasted until approximately 1200 HR during both dates that the study was conducted.

Treatments. Specific row-end spraying scenarios evaluated were:

1) leaving both banks of nozzles on while turning;

2) turning the outside-facing nozzles off (leaving tree-facing nozzles on);

3) turning both banks of nozzles off at the tree trunk;

4) turning all nozzles off at the end of the foliage of the last tree within the row.

Measurement of NON-TARget Deposition. Non-target deposition was measured using $5.1 \times 5.1 \mathrm{~cm}(2 \times$ 2 inches) Teflon spray cards attached at the corners to a cardboard backing using staples. The Teflon targets were hand-cut from sheets of $0.1-\mathrm{mm}$ (0.004 inch) thickness stock. Two of these cards were placed at $8.2-\mathrm{m}(27$ $\mathrm{ft}$ ) intervals on each side of the sprayer along the road bed (total of four targets), and at identical spacing along the roadbed on the opposite side of the lateral canal. Six targets were placed at 8.2-m intervals (between those on the land) within the lateral canal to measure non-target deposition directly to surface water within the grove.

Following each spray application, individual Teflon targets were removed from their respective cardboard backs and placed in $125-\mathrm{mL}(4.2 \mathrm{fl} \mathrm{oz})$ amber glass jars with Teflon-lined caps. Targets were only handled using acid-washed forceps. The jars were then stored at room temperature until analysis.

SAMPLE ANALYSIs. Fifty milliliters of metals-grade acid [ $0.32 \mathrm{M}$ nitric acid $\left(\mathrm{HNO}_{3}\right)+0.12 \mathrm{~m}$ hydrochloric acid $(\mathrm{HCl})]$ were added to each glass jar containing its respective target. The jar was then tightly capped and vortexed on high for $60 \mathrm{~s}$ in the upright position. The bottle was then inverted and vortexed for another $60 \mathrm{~s}$. The bottle was finally inverted once more and vortexed for another $60 \mathrm{~s}$. The acid extract was then transferred into a $125-\mathrm{mL}$ glass beaker (July study) or $70-\mathrm{mL}$ plastic digestion tube (June study). The jar and Teflon targets were then rinsed three times separately into the digestion vessels. Samples were next placed on a hot plate (July study) or in a ModBlock (CPI International, Santa Rosa, Calif.) (June study) to reduce the volume to approximately $20 \mathrm{~mL}$. After refluxing for $30 \mathrm{~min}$, samples were cooled and then diluted up to $50 \mathrm{~mL}$. Percent recovery studies showed no differences between the two digestion/volume reduction methods used. Copper within each sample was determined using a ThermoElemental (Waltham, Mass) ICP-MS (model PQ ExCell) and EPA 200.8 analytical protocol (Creed et al., 1994).

Estimation of Deposition. The area evaluated was divided into three distinct zones: 1) ground surfaces adjacent to the sprayer; 2 ) water surfaces within lateral canal; and 3) ground surfaces across the canal from the sprayer. Deposition directly on 
the ground or water surfaces was estimated by multiplying the average mass per unit surface area for the spray targets within each zone by the grove surface area encompassed by each set of targets. Deposition on each ground target was assumed to be representative of deposition on the surrounding $67.7-\mathrm{m}^{2}\left(729 \mathrm{ft}^{2}\right)$ area $[8.2 \times 8.2 \mathrm{~m}(27$ $\times 27 \mathrm{ft}$ )] . Deposition on each target within the drainage ditch was assumed to be representative of deposition on the surrounding $62.3-\mathrm{m}^{2}\left(670 \mathrm{ft}^{2}\right)$ area $[8.2 \times 7.6 \mathrm{~m}(27 \times 25 \mathrm{ft})]$. Given these assumptions, the total ground surface areas encompassed $338.6 \mathrm{~m}^{2}$ $\left(3645 \mathrm{ft}^{2}\right)$, while the surface area of the water within the ditch was 376.2 $\mathrm{m}^{2}\left(4050 \mathrm{ft}^{2}\right)$.

WEATHER DATA AND ANALYSIS. Mean wind speed, wind direction, $\mathrm{RH}$, and temperature measurements were collected at 15 -min intervals by the Florida Automated Weather Network (FAWN) site at the Indian River Research and Education Center, about $16.1 \mathrm{~km}$ (10 miles) from the experimental site. The southerly vector component of wind speed was calculated using wind speed and direction data from FAWN.

EXPERIMENTAL DESIGN/STATISTICAL ANALYsis. Three replicates of each row-end spraying method were evaluated during each month. Two of the replicates were located on the southern side of the drainage canal, while one was on the northern side. This study utilized a randomized complete-block statistical design, with blocking occurring both spatially and by time. Within applications to each block, the four row-end spraying techniques were applied in a random order to minimize confounding effects of application timing and changing environmental conditions. Deposition data were ranked and analyzed by analysis of variance with means separation at $P=0.05$.

\section{Results}

Results are reported separately by month since data from the two studies were shown to be statistically different. Deposition during the June study was generally greater than that found in the July study. This is not unexpected since a variety of factors, including wind speed and direction, temperature, and humidity, can influence droplet size and non-target deposition. These factors were reviewed by Stover et al. (2002). The RH during the June ap- plication was $82 \%$ when applications began (0845 HR) and decreased to $57 \%$ by the end of applications (1230 $\mathrm{HR})$. The temperature measured at $2.01 \mathrm{~m}(6.6 \mathrm{ft})$ was $27.8^{\circ} \mathrm{C}\left(82^{\circ} \mathrm{F}\right)$ and $32.8^{\circ} \mathrm{C}\left(91{ }^{\circ} \mathrm{F}\right)$ at the beginning and end of the application, respectively. In contrast, the $\mathrm{RH}$ was $95 \%$ at the beginning $(0715 \mathrm{HR})$ of the July application, decreasing to $66 \%$ by the end (1100 HR); while the initial and final temperatures were $23.9^{\circ} \mathrm{C}(75$ $\left.{ }^{\circ} \mathrm{F}\right)$ and $31.7^{\circ} \mathrm{C}\left(89^{\circ} \mathrm{F}\right)$, respectively. A summary of the deposition results obtained follows.

Adjacent to sprayer. Deposition on land surfaces adjacent to the sprayer was calculated based on a total area of $338.6 \mathrm{~m}^{2}[8.2 \times 41.1 \mathrm{~m}(27 \times$ $135 \mathrm{ft}$ )] between the end of the tree rows and edge of the canal. Copper deposition adjacent to the sprayer was statistically more similar among the four treatments in June than in July (Fig. 3). On both study dates, turning the outside nozzles off at the foliage edge through the turn resulted in less deposition than when leaving both sets of nozzles on. Turning both sets of nozzles off at the tree trunk, and turning off only the outside-facing nozzles also reduced deposition on the ground surface adjacent to the sprayer. Deposition ranged from 142 to $369 \mathrm{mg}$ $(0.005$ to $0.013 \mathrm{oz})$ in June. In contrast, deposition on the ground surface during the July study was significantly higher when both nozzles were left on through the turn, relative to all of the other treatments. In this case, leaving all nozzles on through the turn resulted in $142 \mathrm{mg}$, compared to $28 \mathrm{mg}(0.001$ $\mathrm{oz})$ for the other treatments.

Within lateral Canal. Deposition on water surfaces within the lateral canal was calculated based on a total area of $376.2 \mathrm{~m}^{2}$ [7.6 m wide $\times 49.4$ $\mathrm{m}$ long $(25 \times 162 \mathrm{ft})]$. Similar deposition patterns were apparent for both months of data (Fig. 3). However, deposition was generally greater during the June study. In both cases, deposition was significantly reduced when the outward-facing, or both banks of nozzles were turned off, regardless of timing. During the June application, an estimated $6747 \mathrm{mg}(0.238 \mathrm{oz})$ was deposited directly on the water surface when all nozzles were left on through the turn, as compared to 2013 to 2892 $\mathrm{mg}(0.071$ to $0.102 \mathrm{oz})$ with the other treatments. During the July study, $2637 \mathrm{mg}(0.093 \mathrm{oz})$ was deposited on the water surface when all nozzles were left on as compared to 340 to 879 $\mathrm{mg}(0.012$ to $0.031 \mathrm{oz})$ with the other treatments. Direct deposition on the water surface was reduced by $57 \%$ to $70 \%$ during the June study and $67 \%$ to $87 \%$ during the July study, depending on row-end spraying strategy, relative to leaving all nozzles on.

OPPOSITE SIDE OF LATERAL CANAL. Row-end spraying strategies did not influence copper deposition on ground surfaces on the opposite side of the drainage canal from the sprayer. Again, deposition during the June event was higher than in the July event. Deposition on the ground surface ranged from 72 to $130 \mathrm{mg}$ ( 0.003 to 0.005 $\mathrm{oz}$ ) during the June application and 16 to $24 \mathrm{mg}$ (0.0006 to $0.0008 \mathrm{oz})$ during the July application.

\section{Discussion}

The row-end spraying techniques compared in this study are representative of those commonly used by the Indian River citrus industry. Continuing to spray from both sides of the sprayer while rounding the row ends, which resulted in highest deposition, has never been a recommended practice but is occasionally observed. These studies illustrate the importance of shutting off the outer nozzles to reduce off-target deposition on water and ground surfaces, but do not indicate a significant difference in the off-target deposition between any of the remaining techniques.

The data document deposition up to $19.8 \mathrm{~m}(65 \mathrm{ft})$ in either direction (perpendicular to the tree rows) from the center of the sprayer turning radius, and are indicative of deposition that might be expected if each technique occurred singly during an application. Ground deposition of spray materials is typically reported to be greatest within $15.2 \mathrm{~m}$ of the sprayer (Salyani and Cromwell, 1992). Caution should be used in extrapolating off-target deposition from commercial citrus production using the data generated in this study. Our data reflect deposition from spraying only the bed-top side of the trees (i.e., traveled from one bedtop to the next). In actual practice, the grower would re-adjust the sprayer (accounting for elevation differences) for the water furrow side of the trees and spray again. Deposition from commercial application would likely have much higher accumulations from the 

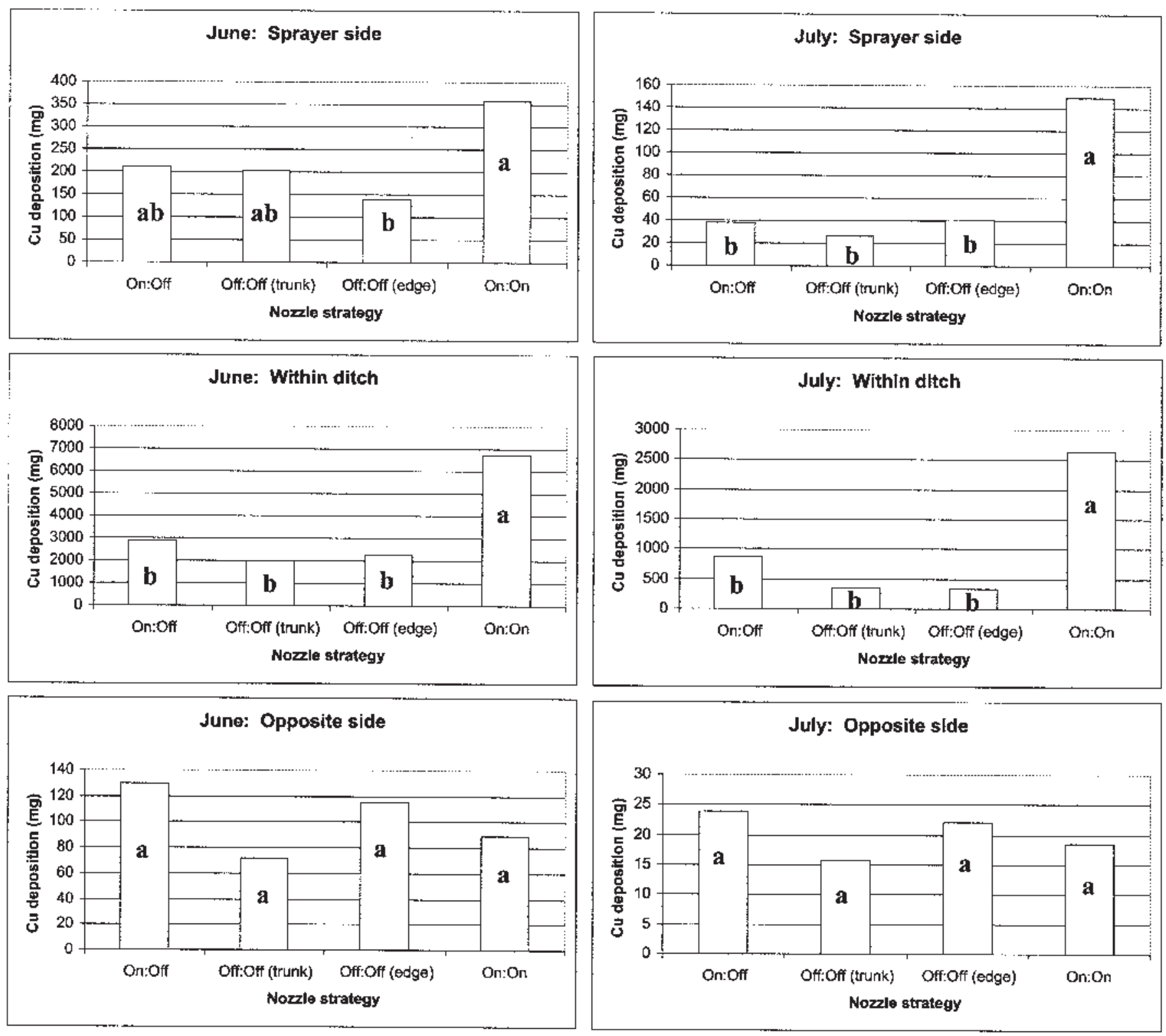

Fig. 3. Copper $(\mathrm{Cu})$ deposition $(\mathrm{mg})$ on ground and water surfaces during the June and July trials. The nozzle strategies were as follows: "On:Off" = leaving tree-facing nozzles on and turning outside-facing off; "Off:Off (trunk)" = turning both sides of nozzles off at the trunk of the last tree before turning into a new row; "Off:Off (edge)" = turning both sides of nozzles off at the edge of the foliage canopy for the last tree in the row before turning into the next; and "On:On" = leaving both the outside-facing and inside-facing nozzles on through the turn into the next row. Bars with the same letters are not significantly different (analysis of variance, $P=0.05) .(28,350 \mathrm{mg}=1 \mathrm{oz}$ ).

combined drift from spraying both sides of the trees along the entire bed as well as additional off-target deposition from spraying nearby tree beds. For example, the citrus block treated in this study consisted of 15 rows of trees planted on raised beds with two rows per bed, and with rows spaced $8.2 \mathrm{~m}$ apart. The tree rows were perpendicular to the 123.4-m-long $(405 \mathrm{ft})$ canal (Fig. 2). Citrus beds were planted on both sides of the canal. In this case, the technician would make eight turns on each side of the canal (furrow-to-fur- row and bed top-to-bed top), giving a total of 16 canal-side turns (Fig. 2). Using the lowest and highest deposition amounts seen in both months to calculate deposition in this case, an estimated 5470 to $46,300 \mathrm{mg}$ ( 0.193 to $1.633 \mathrm{oz}$ ) of copper would be deposited on the water surface when the nozzles were turned off in some manner throughout the turn. An estimated 42,300 to $108,000 \mathrm{mg}$ ( 1.492 to 3.810 oz) would be deposited on the water surface when the nozzles were left on continuously through the turn.
The difference in mean deposition measured on each of the two study dates is quite remarkable. Each of the study dates had very similar wind speed and RH (Fig. 4). The difference in deposition may have resulted from the very different wind direction on the two study dates. The wind directions during the June study date were primarily from the northeast, resulting in a mean wind speed of $5.47 \mathrm{~km} \cdot \mathrm{h}^{-1}(3.4 \mathrm{mph})$ in a southerly vector, which resulted in a greater wind movement between the north-south oriented rows. Even 


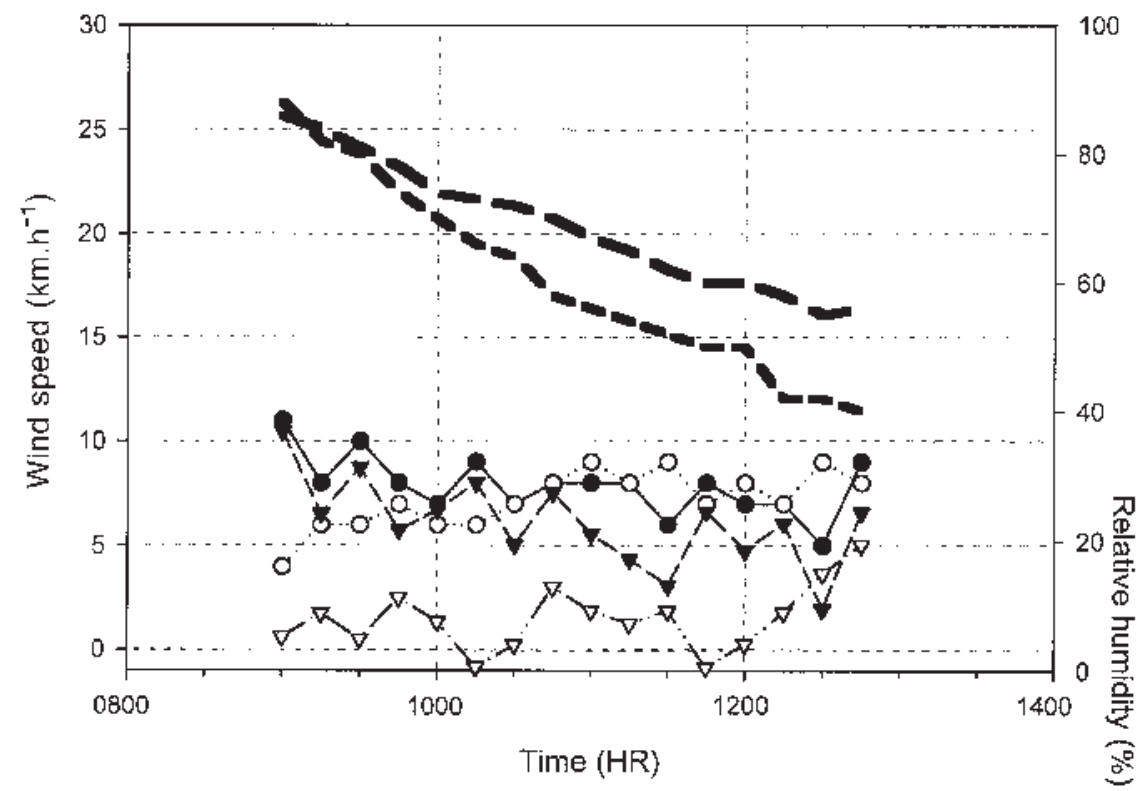

\begin{tabular}{|c|c|}
\hline & Wind speed (June) \\
\hline$\cdots \cdots \cdots$ & Wind speed (utuly) \\
\hline$---\div--\cdots$ & Southerly vector (J une) \\
\hline$-\cdots-\nabla-\cdots-$ & Southerly wector (Ju/y) \\
\hline$=$ & Percent RH (June) \\
\hline 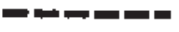 & Percent RH (July) \\
\hline
\end{tabular}

Fig. 4. Average wind speed $\left(\mathrm{km} \cdot \mathrm{h}^{-1}\right)$, southerly vector wind speed $\left(\mathrm{km} \cdot \mathrm{h}^{-1}\right)$, and percent RH during spray applications in June and July. $\left(1 \mathrm{~km} \cdot \mathrm{h}^{-1}=0.62 \mathrm{mph}\right)$.

though wind speed was well within that considered suitable for foliar applications (Stover et al., 2003), it may have significantly influenced off-target deposition.

Development of best management practices (BMPs) typically requires inclusion of some elements based on best professional judgment since it is rare that all aspects can be subjected to replicated scientific studies. Ideally, where competing practices offer economic benefits, scientific studies should be used to verify appropriateness of specified BMPs. The recently published BMP manual for Indian River citrus (Boman et al., 2000) specifically recommends turning the sprayer nozzles off at the trunk of the last tree within rows, followed by making a final pass around the outside perimeter with only the tree-side nozzles operating (wrapping). While our data indicate that this approach reduces off-target deposition relative to continued spraying from outside nozzles, it does not address deposition resulting from the final wrapping application. The additional BMP-specified spray applied along the row ends and perpendicular to the rows during the final wrapping process requires more spray material and worker time, likely resulting in higher costs. In addition, the spray along the row ends will almost certainly contribute additional nontarget deposition on both bed-tops and water furrows. Leaving the inner nozzles on while rounding the tree row is likely to result in much higher applications of the pesticides to the row end relative to the remaining trees in the row, suggesting inefficient use of spray material (Indian River growers, personal communication). Therefore, these data and the accompanying discussion suggest that continuing to spray just to the end of the foliage on the row ends without the added step of wrapping the perimeter should be considered as a new improved BMP to reduce non-target deposition of spray-applied pesticides. Growers should confirm adequate control at the row ends through scouting programs and make application adjustments if needed.

Considering that most groves in the more than 80,937 ha $(200,000$ acre) Indian River citrus production area have similar drainage systems, the possible environmental benefits could be significant. In addition to demonstrating the reduction in direct deposition of a pesticide on water and ground surfaces, these studies also demonstrated the inherent variability that can be expected in non-target deposition, even when applications are made at the same rates and under relatively similar climatic conditions.

\section{Literature cited}

Boman, B.J., P.C. Wilson, and J.W. Hebb (eds). 2000. Water quality/quantity BMPs for Indian River area citrus groves. Florida Dept. of Environ. Protection, Tallahassee.

Creed, J.T., C.A. Brockhoff, and T.D. Martin. 1994. EPA method 200.8: Determination of trace elements in waters and wastes by inductively coupled plasma-mass spectrometry. U.S. Environ. Protection Agency, Office of Res. and Dev., Environ. Monitoring Systems Lab., Cincinnati, Ohio.

Fox, R.D., D.L. Reichard, R.D. Brazee, C.R. Krause, and F.R. Hall. 1993. Downwind residues from spraying a semi-dwarf apple orchard. Trans. Amer. Soc. Agr. Eng. 36:333-340.

Hobson, P.A., P.C. Miller, P.J. Walkgate, C.R. Tuck, and N.M. Western. 1993. Spray drift from hydraulic spray nozzles: The use of a computer simulation model to examine factors influencing drift. J. Agr. Eng. Res. 54:293-305.

Indian River Lagoon National Estuary Program. 1996. The Indian River lagoon comprehensive conservation and management plan. Indian River Lagoon Natl. Estuary Program, Melbourne, Fla.

Johnson, D.R. 1995. Drift from orchard airblast applications: Integration and summary of 1993 and 1994 field studies Rpt. No. I95-004, Spray Drift Task Force, Washington, D.C.

Salyani, M. and R.P. Cromwell. 1992. Spray drift from ground and aerial applications. Trans. Amer. Soc. Agr. Eng. 35:1113-1120.

Spray Drift Task Force. 1997. A summary of airblast application studies. 31 May 2002. <http://www.agdrift.com/PDF_FILES/ airblast.pdf $>$.

Stover, E., D. Scotto, C. Wilson, and M. Salyani. 2003. Pesticide spraying in grapefruit: II. Overview of factors influencing spray efficacy and off-target deposition. HortTechnology 13:166-177.

Walklate, P.J. 1992. A simulation study of pesticide drift from an air-assisted orchard sprayer. J. Agr. Eng. Res. 51:263-283. 